\title{
Experimental investigation of frost induced damage of cement mortar
}

\author{
Alicja Wieczorek ${ }^{1,}$, Marcin Koniorczyk $^{1}$, and Kalina Grabowska ${ }^{1}$ \\ ${ }^{1}$ Department of Building Physics and Building Materials, Lodz University of Technology, 90-924 \\ Lodz, Al. Politechniki 6, Poland
}

\begin{abstract}
Questions connected to influence of frost degradation on microstructure and physical properties of water saturated cement mortars and their resistance to cyclic water freezing are the objectives of research. The main aim of the investigation is to analyze the ice-induced deterioration of cement mortars with different water/cement ratios $(\mathrm{w} / \mathrm{c}=0.50$ and 0.40$)$ in a accelerated durability tests. The changes of pore size distribution and water absorption coefficient are investigated by means of mercury intrusion porosimetry and capillary absorption test. Additionally, the analysis of the impact of drying temperature $\left(40^{\circ} \mathrm{C}, 60^{\circ} \mathrm{C}\right.$, $80^{\circ} \mathrm{C}$ and $105^{\circ} \mathrm{C}$ ) on the microstructure is introduced.The performed tests enabled to estimate that the destruction of the cement matrix and the range of observed changes depend on the initial pore size distribution and their volume in the cement matrix. It is also established that the increase of transport properties is correlated with the change of pore size distribution. The obtained results allow to conclude a decrease of content of small pores (up to $150 \mathrm{~nm}$ ) and increase of larger pores for mortar with $\mathrm{w} / \mathrm{c}=0.50$. Application of superplasticizer, which resulting in reduction of water to cement ratio up to 0.40 , allows to obtained resistant to 150 frost cycles cement mortar.
\end{abstract}

\section{Introduction}

In the civil engineering, cement-based materials are frequently exposed to aggressive environment such as cyclic water freezing. The range of destruction is dependent mainly on the amount of a fluid penetrating the material [1]. The porous materials are built of the solid skeleton and the pores (different types of pores with different pore sizes), which might be filled with the gaseous and the liquid phase. The liquid phase contains, besides the water, various types of contaminations, which migrate into the material through the system of interconnected pores. Therefore, the microstructure is one of the most important characteristics, which estimates the durability of cement based materials [2]. Porosity is the main parameter, which determines strength and influences transport properties, e.g. permeability. Therefore the knowledge about the porosity and the pore size distribution is extremely important considering the frost durability of the material [3, 4]. It is acknowledged that due to the frost-induced damage mechanical properties are considerably

*Corresponding author: alicja.marciniak@p.lodz.pl 
reduced [5]. Furthermore, cyclic water freezing impacts the material transport properties [6]. The main objective of the investigation is to analyze the ice-induced deterioration of cement-based materials in a accelerated durability tests. Therefore, the application of airentraining admixtures in prepared materials is deliberately rejected. The purpose of the experimental study is to examine experimentally the effect of cycling water freezing on the microstructure and transport properties of cement mortar. The mercury intrusion porosimetry has been used to verify influence of the ice formation on the pore size distributions. The water absorption coefficient is determined using capillary absorption test. Moreover, the paper presents a study of the impact of drying temperature $\left(40^{\circ} \mathrm{C}, 60^{\circ} \mathrm{C}\right.$, $80^{\circ} \mathrm{C}$ and $105^{\circ} \mathrm{C}$ ) on the microstructure of cement mortar with $\mathrm{w} / \mathrm{c}=0.40$.

\section{Materials and Methods}

Experiments have been performed on cement mortar specimens with different water to cement ratios (w/c equal to 0.5 and 0.4 ). All the composites are produced on the basis of Portland cement CEM I $42.5 \mathrm{~N}-\mathrm{NA}$ and CEN Standard sand. The details of the mixture proportions of cement mortar are given in Table 1.

In order to achieve high degree of hydration and a uniform saturation the samples, $40 \times 40 \times 160 \mathrm{~mm}$, are cured in tap water at $20 \pm 1 \mathrm{C}$ for 90 days. After completion of the conditioning, the specimens are undergone an assessment of their resistance to frost.

Table 1. Cement mortar mixture proportions

\begin{tabular}{|c|c|c|c|c|c|}
\hline Series & Cement $[\mathbf{g}]$ & Sand $[\mathbf{g}]$ & Water $[\mathbf{g}]$ & Plasticizer $[\mathbf{g}]$ & $\mathbf{w} / \mathbf{c}[-]$ \\
\hline ZN_1 & \multirow{2}{*}{900} & 2700 & 360 & 18 & 0.40 \\
\cline { 1 - 4 } & & & 450 & 0 & 0.50 \\
\hline
\end{tabular}

\subsection{Freeze and thaw cycles}

At the beginning one has to subject the studied samples to frost damage. Saturated cement mortars are divided into two groups. One group is prepared for frost tests, whereas the second one is left in the water bath and used as a set of control samples. The temperature changes are imposed by the accelerated freeze-thaw climatic chamber, according to PN$88 / \mathrm{B}-06250$ [7]. The freezing of the specimens is carried out at $-20^{\circ} \mathrm{C}$ for $4 \mathrm{~h}$, while the thawing is performed in water at $+20^{\circ} \mathrm{C}$ and lasts $2 \mathrm{~h}$. Four samples, $40 \times 40 \times 160 \mathrm{~mm}$, of each series and each number of freeze-thaw cycles $(0,50,100$ and 150 freeze-thaw cycles) are divided into two parts of sizes $40 \times 40 \times 80 \mathrm{~mm}$. From one part (four samples of each number of freeze-thaw cycles), 5 cores of diameter equals to $10 \mathrm{~mm}$ and height equals to $15 \mathrm{~mm}$ are selected from the centre of the beams for the porosimetry test. The second part is used for the capillary absorption test. When water adsorption test has been completed, silicon is removed from the bottom of the samples and compressive strength test is conducted.

\subsection{Mercury intrusion porosimetry}

The research program includes measurement of microstructure parameters of cement mortars in order to perform a qualitative and quantitative assessment of the porosity structure after water freezing. Structural tests are conducted using the mercury intrusion porosimetry (MIP) by means of porosimeter AutoPore IV 9500. For the applied pressure, pores of diameter from $6 \mathrm{~nm}$ up to $100 \mu \mathrm{m}$ can be detected. The MIP method requires 
complete removal of water from the sample before mercury pressure is applied. If the sample is not completely dried, water will remain in the pore system. As a consequence, the MIP curve will give inaccurate or incomplete information on the total porosity and on the pore size distribution. On the other hand drying may result in structural and physical collapse of hydrates, which can damage the microstructure of the cement matrix [8].

In order to obtain a relatively suitable temperature of oven drying, four steps of temperature: $40^{\circ} \mathrm{C}, 60^{\circ} \mathrm{C}, 80^{\circ} \mathrm{C}$ and $105^{\circ} \mathrm{C}$, are selected for comparison. Isopropanol exchange followed by vacuum drying at $30^{\circ} \mathrm{C}$ are used as the references method. Samples with $\mathrm{w} / \mathrm{c}$ ratio $0.4, \mathrm{ZN} 1$, at 365 days of curing age are used for this purpose. The 25 cores of diameter equals to $10 \mathrm{~mm}$ and height equals to $15 \mathrm{~mm}$ are separated into five groups and exposed to five different drying procedures. Water loss is monitored each 24 hours until weight stability is reached - until a stable mass loss of $0.01 \%$ /day is gained. The effects of different value of oven-drying temperature on the pore size distribution of cement mortar ZN1 are summarized in Figure 1a. The presented results indicate that the temperature of oven-drying has a significant impact on the microstructure of cement mortar. Thus, as the value of oven-drying temperature increases, not only does the total porosity increase but also the dominant pores shift towards bigger diameters. In the case of drying the specimens at $80^{\circ} \mathrm{C}$, double increase in the dominant pore size is noted. Oven-drying at high degrees is apparently not only coarsening the pores but also altering the connectivity of the whole pore structure. Therefore, as the temperature increases up to $105^{\circ} \mathrm{C}$, the $\mathrm{dV} / \mathrm{d} \log \mathrm{D}$ distribution may be bimodal in character. Further analysis of the resultant distribution of the structure of pores consisted in dividing the entire range of pores into three classes: mesopores $(<50 \mathrm{~nm})$, middle capillary pores $(50 \div 100 \mathrm{~nm})$ and larger capillary pores $(>100 \mathrm{~nm})$, Fig. 1b. It is clearly visible that an increase of the value of oven-drying temperature causes a greater capillary porosity. For example, in samples dried at $60^{\circ} \mathrm{C}$, capillary pores accounted for $24 \%$, while in specimens at $105^{\circ} \mathrm{C}$, this amount increased to $45 \%$. Obviously, as the number of capillary pores increases, the number of mesopores, pores with a diameter below 50nm, falls. Thus, after careful comparison, influence of temperature on microstructure and time of preparation samples before the measurements, the oven drying at $60^{\circ} \mathrm{C}$ is applied for all the specimens.
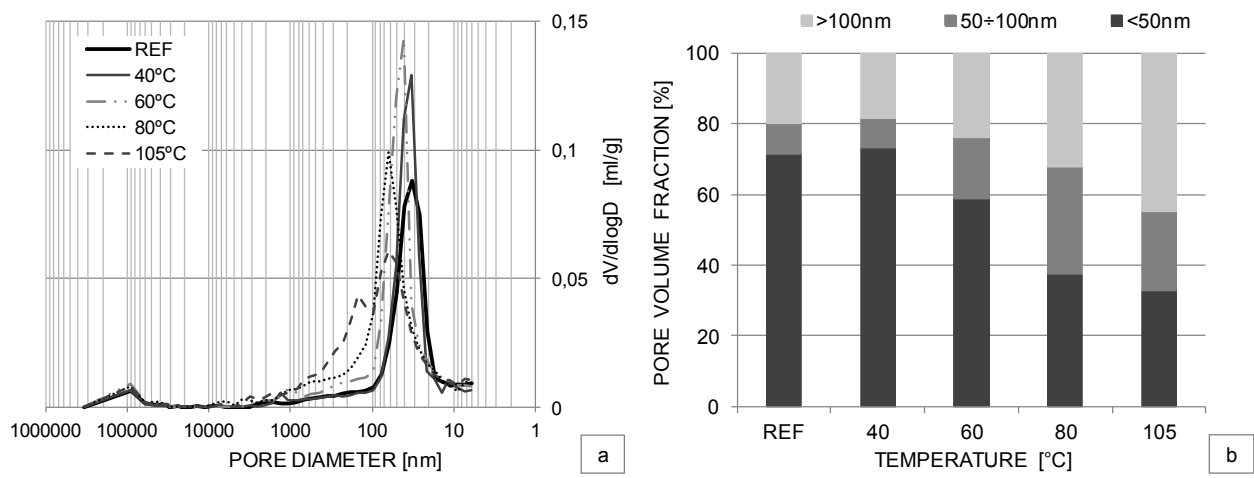

Fig. 1. Comparison of: (a) the pore size distribution (the average of five measurements) and (b) pore volume distribution of cement mortar with pore classification.

\subsection{Capillarity test}

Standard procedures PN-EN ISO 15148 [9] of determining the water absorption coefficient, $A\left[\mathrm{~kg} /\left(\mathrm{m}^{2} \cdot \mathrm{s}^{1 / 2}\right)\right]$, due to capillary action consist in weighing samples in a given time intervals throughout 90 minutes or 24 hours. Samples are dried to constant mass, and then one face of the specimens is immersed in water at a depth of 5-10mm. For this experiment, 
measurements are performed at the following intervals: 5 and 20min and 1, 2, 3, 4, 6, 8, 12 , $24 \mathrm{~h}$. The uncontrolled exchange of moisture with the surrounding environment is prevented by silicon. Water absorption coefficient is mathematically defined as a tangent to capillary water content function and expresses the rate of capillarity action in certain time:

$$
A=\Delta \mathrm{m}_{\mathrm{t}} /(F \cdot \sqrt{ } t)
$$

where $\Delta m_{t}$ is the mass change of the of the sample [kg] during time $t[\mathrm{~s}]$ and $F$ is the sample surface area in direct contact with water $\left[\mathrm{m}^{2}\right]$.

\section{Results}

\subsection{Pore size distribution}

The comparison of the average of five measurements of pore size distribution for series 0.40 and 0.50 , before and after freeze-thaw cycles, is shown in Figure $2 \mathrm{a}$ and $2 \mathrm{~b}$, respectively. Pore size distribution for control samples has a unimodal character, which predominant pore diameter of about $50 \mathrm{~nm}$ for mortars 0.50 and $40 \mathrm{~nm}$ for 0.40 . With the increasing number of freeze-thaw cycles for cement mortar 0.50 , the visible destruction of pores can be observed and the differential pore size distribution becomes bimodal. It is stated that with further increase of $\mathrm{f}-\mathrm{t}$ cycle, the number of the second maximum is formed by pores of diameter around $800 \mathrm{~nm}$. Meanwhile, after $150 \mathrm{f}$-t cycles the second dominant pore size is shifted up to $2.5 \mu \mathrm{m}$. The obtained results allow to conclude a decrease of content of small pores (up to 150nm) and increase of larger pores (with diameter ranges from $200 \mathrm{~nm}$ to $10 \mu \mathrm{m}$ ), which indicate damage of thin channels in the pore structure for mortars with $\mathrm{w} / \mathrm{c}=0.50$, Fig. $2 \mathrm{~b}$. Application of superplasticizer, which results in reduction of water to cement ratio up to 0.40 , allows to obtained resistant to 150 frost cycles cement mortar. Moreover, with the increasing number of $\mathrm{f}-\mathrm{t}$ cycles, no further destruction of the pore structure is noticed.
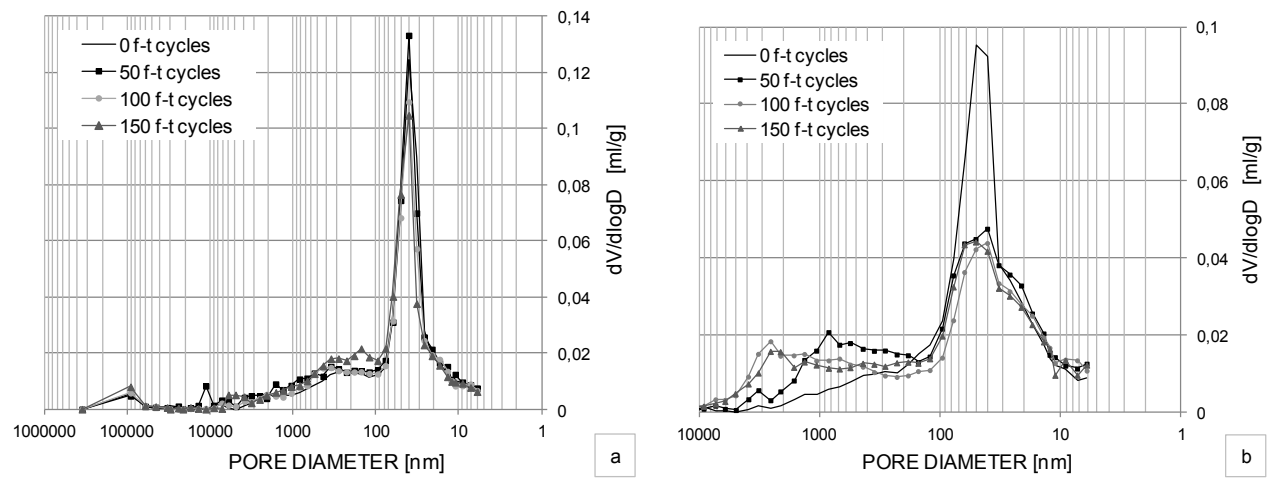

Fig. 2. Comparison of the pore size distribution (the average of five measurements) obtained by means of MIP for series $0.40[\mathrm{w} / \mathrm{c}=0.40]$ (a) and $0.50[\mathrm{w} / \mathrm{c}=0.50]$ (b) after freeze-thaw cycles.

\subsection{Capillary absorption test}

The results of the average value of water absorption coefficient after a given number of freeze-thaw cycles are presented in Figure 3. Comparing the obtained experimental data, one can observe that the transport properties are related to the pore size distribution and interconnectivity of the pore system of cement mortars. For samples with the lower value of 
$\mathrm{w} / \mathrm{c}=0.40$, after $150 \mathrm{f}-\mathrm{t}$ cycles, one can observe that the value of water absorption coefficient does not change. The water suction by samples, which have been subjected to freezing-thawing cycles, is faster for specimens with the w/c equals to 0.50 . The rate gradually increases with a number of cycles. The narrow channels between the pores are broken, which is manifested by a faster water uptake. For sample of series 0.50 (Fig. 3b) the water absorption coefficient after 100 and 150 freeze-thaw cycles increases about $15 \%$ and $20 \%$. In particular, it is associated with increase volume of pores with diameters larger than $150 \mathrm{~nm}$, notably the second peak in differential pore size distribution.
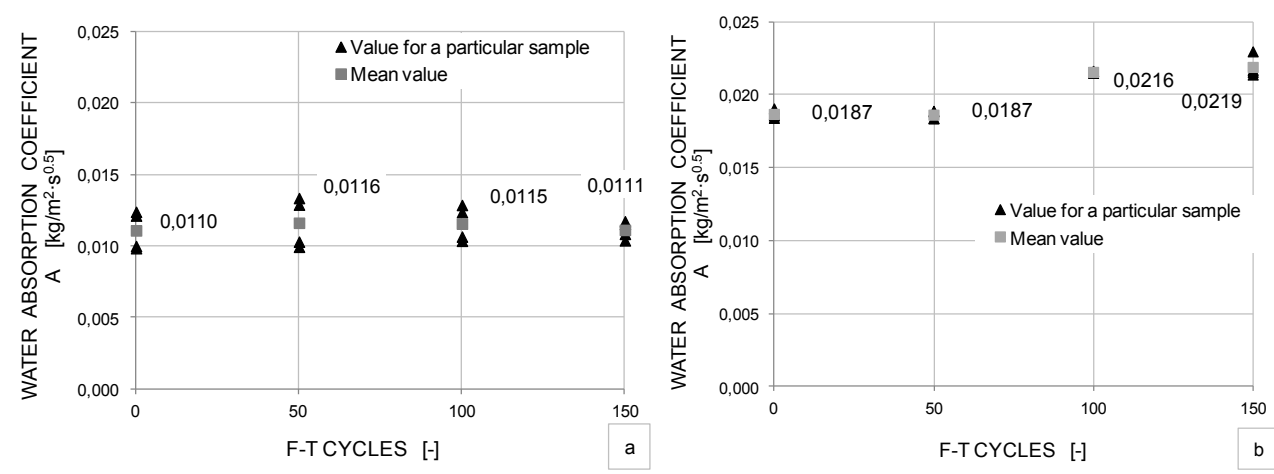

Fig.3. Evolution of cement mortars water absorption coefficient due to freezing-thawing cycles for: (a) $0.40[\mathrm{w} / \mathrm{c}=0.40]$ and (b) $0.50[\mathrm{w} / \mathrm{c}=0.50]$.

\subsection{Mechanical properties of cement mortars}

The values of compression strengths for tested cement mortars after different number of cycles are presented in Table 2 . The presented results are the average of four measurements of each series and each number of freeze-thaw cycles. The small number of specimens could affect the accuracy of the results. Additionally, the error, defined as the maximum difference between results obtained for particular specimens and their average value, is evaluated. The freeze-thaw test showed that the addition of superplasticizer, which allowed to reduce water to cement ratio up to 0.4 , result in satisfactory frost-resistance mortar after 150 freeze-thaw cycles, whereas in the reference mortar $(\mathrm{w} / \mathrm{c}=0.5)$ around $28 \%$ decrease of compressive strength is noted.

Table 2. The average values of compressive strengths after: $0,50,100$ and 150 freeze-thaw cycles

\begin{tabular}{|l|c|c|c|c|}
\hline \multirow{2}{*}{ Series } & \multicolumn{4}{|c|}{ Compressive strength [MPa] } \\
\cline { 2 - 5 } & \multicolumn{4}{|c|}{ Number of freeze-thaw cycles [-] } \\
\cline { 2 - 5 } & $\mathbf{0}$ & $\mathbf{5 0}$ & $\mathbf{1 0 0}$ & $\mathbf{1 5 0}$ \\
\hline ZN_2 & $62.0 \pm 5.9(-)$ & $60.3 \pm 5.3(2.8 \%)$ & $59.4 \pm 5.8(4.2 \%)$ & $57.7 \pm 5.1(7.0 \%)$ \\
\hline ZN_1 & $56.2 \pm 3.6(-)$ & $46.0 \pm 4.2(18.2 \%)$ & $41.0 \pm 1.5(27.0 \%)$ & $40.7 \pm 4.7(27.7 \%)$ \\
\hline
\end{tabular}




\section{Conclusions}

The following conclusions may be drawn from the mentioned results:

- the internal frost damage of cement-based materials with $\mathrm{w} / \mathrm{c}=0.50$ is more extensive. After $150 \mathrm{f}$-t cycles, the compressive strength of mortars 0.50 goes down $28 \%$ of its initial value. Moreover, with the increasing number of freeze-thaw cycles, the visible destruction of pores can be observed and the differential pore size distribution becomes bimodal. Gradual ice-induced destruction of pore structure causes an increase of volume of pores with diameter ranges from $200 \mathrm{~nm}$ to $10 \mu \mathrm{m}$. It is also established that such a variation in the pore structure induces an increase of water absorption coefficient;

- the undertaken material modification, addition of superplasticizer which allowed to reduce water to cement ratio up to 0.4 , results in satisfactory frost-resistance of mortar (150 freeze-thaw cycles).

\section{References}

1. H. Hilsdorf, J. Kropp, Performance Criteria for Concrete Durability, Rilem Report 12, CRC Press (2005)

2. P. K. Mehta, P. J. M Monterio, Concrete: Microstructure, Properties, and Materials Third ed., McGraw-Hill, New York (2006)

3. M. Pigeon, R. Pleau, Durability of Concrete in Cold Climates. Modern Concrete Technology Series, Taylor \& Francis (1995)

4. Z. Wang, Q. Zeng, Y. Wu, L. Wang, Y. Yao, K. Li, Constr. Build. Mater. 62 (2014)

5. G. Wardeh, M. A. S. Mohamed, E. Ghorbel, J. Build. Phys. 35 (2010)

6. M. Saito, M. Ohta, H. Ishimori, Cement and Concrete Composites 16 (1994)

7. PN-B-06250:1988, Polish Standard: Normal Concrete (1988)

8. C. Galle, Cem. Concr. Res. 31 (2001)

9. EN ISO 15148:2002. Hygrothermal performance of building materials and products Determination of water absorption coefficient by partial immersion 